\title{
Educação e justiça social na contemporaneidade: repensando o sentido da docência no âmbito escolar
}

\author{
Education and social justice on contemporaneity: \\ rethinking the sense of teaching in the school environment
}

Educación y justicia social en la contemporaneidade:
repensar el sentido de la docencia en el entorno escolar

Sidinei Pithan da Silva*

\section{Resumo}

O estudo tematiza novos horizontes para pensar a educação na contemporaneidade, a partir dos marcos referenciais modernos e pós-modernos que envolvem a ideia de justiça social, procurando desdobrar implicações para pensar o sentido da docência no âmbito escolar. O estudo ampara-se na defesa de um pensamento complexo, capaz de permitir a emergência de novas formas de sensibilidade e racionalidade para com a questão educacional, o que pode significar um dimensionamento amplo para a ideia de justiça social, bem como de espectro acerca do que constitui a atividade docente. O repensar da docência no âmbito escolar envolve a compreensão de seu caráter dinâmico, contraditório e complexo, o que significa assinalar seu envolvimento com os problemas do mundo sociais e históricos e suas relações com o universo das ciências, das subjetividades e do mundo do trabalho. Os sentidos implicados na ideia de justiça social desafiam os educadores a não apenas compreender o curso dos acontecimentos do mundo moderno/contemporâneo nas quatro esferas do mundo humano, como também, fundamentalmente, reconfigurar e avaliar seus modos de intervenção crítica na realidade educacional, tendo em vista o combate das (in)justiças globais e contingentes que se exacerbam no capitalismo.

Palavras-chave: Docência. Educação. Justiça social. Modernidade. Pós-Modernidade.

\section{Abstract}

The study thematizes new horizons to think education on contemporary world from the modern and postmodern frameworks implied in the idea of social justice, seeking to unfold implications to think the sense of teaching in the school context. In general terms, the study is based on the defense of a complex thinking, able to allow the emergence of new forms of sensitivity and rationality to educational question, which could mean a broad dimension to the idea of social justice, as well as spectrum of what constitutes the teaching activity. The teaching rethinking in the school context involves the understanding of its dynamic, contradictory and complex character, which means to indicate its involvement with problems of social and historical world and its relations

Recebido em 15/03/2019 - Aprovado em 05/07/2019

http://dx.doi.org/10.5335/rep.v26i3.9324

Doutor em Educação pela Universidade Federal do Paraná. Professor do curso de Educação Física e do Programa de Pós-Graduação em Educação nas Ciências, mestrado e doutorado, da Universidade Regional do Noroeste do Estado do Rio Grande do Sul. Brasil. ORCID: 0000-0001-6400-4631. E-mail: sidinei.pithan@unijui.edu.br 
with the universe of sciences, subjectivities and the world of the job. The involved senses in the idea of social justice challenge educators not only to understand the course of the events of the modern / contemporary world in these four spheres of the human world, but fundamentally reconfigure and evaluate their modes of critical intervention in educational reality, in order to combat global (in)justice and contingents that exacerbates capitalism.

Keywords: Teaching. Education. Social justice. Modernity. Postmodernity.

\section{Resumen}

El estudio tematiza nuevos horizontes para pensar la educación en la actualidad a partir de marcos referenciales modernos y pos modernos implicados en la idea de justicia social, intentando desvelar implicancias para pensar el sentido de la docencia en el ámbito escolar. El texto se posiciona en defensa del pensamiento complejo, en tanto permite la emergencia de nuevos modos de sensibilidad y racionalidad en relación con lo educativo, aportando elementos que amplían la mirada, y otorgan nuevos sentidos a la idea de justicia social y a lo que significa la tarea docente. Repensar la docencia en el marco del sistema educativo, implica comprender su carácter dinámico, contradictorio y complejo; lo que significa asumir su relación con su contexto histórico social y sus vínculos con el mundo de las ciencias, las subjetividades y el mundo del trabajo. Los sentidos involucrados en la idea de justica social desafían a los educadores no solo a comprender el curso de los acontecimientos del mundo moderno/contemporáneo en estas cuatro dimensiones del mundo humano, sino también a reconfigurar y evaluar fundamentalmente de manera crítica sus modos de intervención en la realidad educativa, en vista de la batalla de la (in)justicia global y contingente que exacerba el capitalismo.

Palabras clave: Docencia. Educación. Justicia Social. La Modernidad. La Posmodernidad.

\section{Introdução}

Os novos cenários sociais, políticos e culturais contemporâneos desafiam a repensar a educação, bem como os saberes e ações indispensáveis para a docência. E o tema da justiça social funciona como uma forma de horizonte que desafia a rever os modos de conceber a educação e seu entrelaçamento com os tecidos social, epistêmico, político e cultural. Esse tema também coloca questões de ordens filosófica e pedagógica acerca do estatuto da identidade docente em tempos de modernidade líquida/flexível. As perguntas mais fundamentais já enunciadas por Kant (1980) no século XVIII, acerca do que se pode saber, o que se deve fazer e o que se pode esperar, movimentam para pensar um sentido possível para o conhecimento, a educação e a ação no devir do mundo social e histórico. Essas interrogações exigem, grosso modo, não apenas uma capacidade funcional por parte dos docentes (adaptativa), mas, sobretudo, uma capacidade instituinte e mediata (reflexiva). Condição que desafia a universidade, a escola e os envolvidos com o trato da questão educacional a rever e repensar permanentemente a natureza dos saberes constitutivos da ação docente. 
Para aproximar o debate acerca de um novo estatuto teórico para a justiça social, com a problemática da docência e da educação, na interface do debate modernidade/pós-modernidade, o texto procura compreender, a partir de um estudo bibliográfico, de cunho interpretativo, a crise de sentidos que ronda o cotidiano docente em tempos de modernidade líquida/flexível, bem como o próprio universo de crise das ciências humanas. Sugere, para tanto, que, mesmo sendo problemáticas complexas e pertencentes a universos diferentes, acabam por ganhar uma significação relacionada com a crise do próprio projeto social moderno. Tanto as aspirações por justiça social quanto o próprio fundo teórico e paradigmático da filosofia e das ciências humanas, que animaram o projeto social e educacional moderno, entraram em crise no final do século XX e convocam a repensar a modernidade e a educação nesse contexto. Nesse sentido, a pergunta que anima se refere à dúvida radical acerca do modo de pensar a educação na interface do debate modernidade/ pós-modernidade. Como pensar a educação, a docência e a justiça social na crise do projeto social moderno? Seria possível construir uma outra noção complexa de racionalidade/sensibilidade para pensar a docência, a justiça social e a educação escolar na contemporaneidade?

O filósofo Richard Rorty (1999), um liberal e crítico radical da esquerda, ao examinar a crise do projeto social moderno, compreendeu e interpretou os dois marcos centrais da política norte-americana ao longo do século XX. Da primeira parte do século até meados de 1960, predominou uma esquerda igualitarista, que se empenhou enormemente para buscar níveis melhores de vida para os trabalhadores. Na segunda parte do século, emerge uma esquerda culturalista, que se dedicou à problemática das minorias excluídas, dos homossexuais, das mulheres, das discriminações e opressões de gênero. Rorty (1999) mapeia bem os excessos de ambos os discursos, quando afirma que os primeiros eram machistas e homofóbicos, e os segundos atribuem pouco valor ao drama do trabalho e das questões de classe e de busca de igualdade social.

A posição de Rorty (1999) parece, em linhas gerais, reafirmar uma certa valorização do espírito ocidental (liberal) e dos valores civilizatórios e democráticos, demarcando um interesse pragmatista para com a educação, a igualdade e a democracia. Muitos teóricos conservadores, como Harold Bloom e, inclusive, Richard Rorty, têm buscado destacar que o lugar das instituições educacionais se refere à construção de uma cultura comum, em detrimento de uma política cultural. Rorty está muito mais alinhado com uma ideia de justiça relacionada com as problemáticas da igualdade, da democracia e da liberdade política dentro de uma agenda 
modernista. Esses pontos, obviamente, são defensáveis, mas, no entanto, o autor, conforme tem compreendido Henry Giroux (2003), tem separado o político do cultural e, com isso, tem limitado a ação da educação no âmbito da questão de políticas que sejam cegas "à cor, uma política para a qual a questão da diferença seja amplamente irrelevante para um materialismo ressurgente que se define como a antítese do cultural" (GIROUX, 2003, p. 34). Giroux (2003) entende que Rorty promove uma caricatura da esquerda cultural e, em nome de questões gerais, esquece formas específicas de opressão. Com essa posição, Giroux (2003) aponta o valor de categorias pós-modernistas para o debate educacional, a agência docente e a questão da justiça social.

Nesse contexto, o modo como se propõe pensar estes temas (justiça social, docência e educação) não é por exclusão do que foi considerado importante pela tradição modernista (igualdade, liberdade e fraternidade), para definir o lugar e o papel da escola e da educação em relação à política, ao combate à desigualdade, ou mesmo por descarte do que tem sido sugerido pela tradição pós-modernista (identidades, diferenças e alteridades), e ao combate às formas específicas de opressão que se dão em torno de identidades de gênero, etnia e raça. Advoga-se em torno da necessidade de um pensamento complexo/dialético para refletir a formação docente e a justiça social na educação em tempos líquidos/flexíveis, o que compreende, sobretudo, novas racionalidade e sensibilidade complexas, as quais comportem a capacidade de ler de forma ambivalente e contraditória as heranças das tradições modernistas e pós-modernistas. Essa condição modifica a noção acerca dos saberes e conhecimentos que são constitutivos do agir docente, com vistas à justiça social no interior das práticas pedagógicas escolares.

Isso parece implicar uma defesa da universalidade, e não do universalismo homogeneizante, como também da singularidade e da diferença, não do particularismo e da fragmentação. Indica ainda que é preciso, na atividade docente, romper com o cientificismo moderno (ou com o caráter aparentemente neutro da ciência), sem perder de vista os horizontes de busca da igualdade e da liberdade proclamados pelos pensamentos político e social modernos. Significa que a escola, em tempos de modernidade líquida/flexível, pode continuar investindo na construção de uma cultura comum (plural) em torno do conhecimento, que favoreça a participação na esfera pública (política); como também incorporar formas novas de pensar o sentido da ação docente em perspectivas curriculares de inclusão social, que problematizem as políticas culturais e identitárias e seus contextos sociais e econômicos, dando voz e vez aos subalternos, excluídos e explorados. A questão da 
justiça social parece mobilizar para tal agenda, sugerindo uma articulação complexa entre liberdade política, igualdade social, diferença cultural e solidariedade, obrigando a fazer uma análise e uma rearticulação dos legados e heranças das culturas modernistas e pós-modernistas de pensamento na educação.

\section{Educação e justiça social: entre a modernidade e a pós-modernidade}

O debate sobre justiça social e educação não produz nem pede automaticamente uma adesão (militante), nem assim poderia ser. Pelo contrário, exige uma capacidade de questionamento acerca do que constitui a educação em seu projeto moderno (XVIII) e contemporâneo (XXI). Ou seja, trata-se de compreender como a questão educacional tornou-se constitutiva das formas de sociabilidade produzidas pelas sociedades modernas e contemporâneas em seu dinamismo de produção e autoprodução de subjetividades. Esse movimento leva a interrogar e questionar o próprio imaginário moderno/contemporâneo e seu conjunto de idealidades, instituições e práticas sociais (ancoradas em pressupostos filosóficos, políticos, éticos e culturais). A consciência histórica, como enunciou Gadamer (1998) nos rastros de Hegel, ajuda a perceber que o mundo tem história e não se reduz à vontade individual. Em sentido semelhante, Marx lembra, em O 18 Brumário de Luís Bonaparte (2011), o quanto as tradições do passado estão envolvidas nas revoluções e nos acontecimentos do presente. Segundo ele, "a tradição de todas as gerações passadas é como um pesadelo que comprime o cérebro dos vivos" (MARX, 2011, p. 25).

Esse reconhecimento, tanto por parte de Gadamer (1998) como de Marx (2011), sugere sempre uma leitura atenta não apenas da forma como se apresenta o mundo (interpretação imediata) para nós, ou de como ele deveria ser no futuro (justo), mas, fundamentalmente, de como é produzido nas formas de pensamento no interior do mundo social e histórico (interpretação mediata). Importante lembrar que o próprio Marx, no intento de compreender o mundo moderno, buscou desenvolver a crítica da filosofia hegeliana, a qual ele considerava ser o modo de expressão mais elaborado sobre o mundo moderno. Em Hegel, no âmago de sua filosofia, Marx (2005) imaginou encontrar a estrutura do mundo moderno e da dominação de classe. Nesse sentido, Marx pode ser lido, também, como um crítico das ideologias. Essa última questão (como se pode pensar ou questionar as ideologias e imaginários que nos produzem) remete às duas anteriores (o que o mundo é e o que ele deveria ser) em um sentido circular e permite uma aproximação com a problemática da educação em seu vínculo com a justiça social. Em uma clara alusão ao 
problema do pensar, ela remete também a Kant (1980) e ao tema do conhecimento do conhecimento, como tem sugerido Edgar Morin (2001) em sua insistente defesa da necessidade de um pensamento complexo. Movimento que também aproxima da perspectiva de uma dialética negativa, tal como a formulada por Theodor Adorno (2009). Nesse contexto, Giacóia Junior, ao interpretar a filosofia de Theodor Adorno e pensar as heranças do universalismo moderno e do particularismo pós-moderno, dá a seguinte pista:

Acompanhemos, portanto, com Adorno, como essa fratura entre o universal e o singular pode ser pensada sem negação absoluta de nenhum dos pólos e com vistas a possibilidade de conservar o momento dialético de verdade que ambos reivindicam, sem resvalar nem em um universalismo totalitário, nem na diáspora dos particularismos pós-modernos (2001, p. 72).

A pergunta clássica de Marx e Engels, enunciada na obra A ideologia alemã (2009), sobre quem educará os educadores, é retomada por Edgar Morin (2001), como metáfora para pensar o dinamismo e as contradições do mundo moderno e o lugar que nele ocupam os educadores. Certamente Morin é muito mais kantiano do que marxiano, quando sugere que se deve repensar o já pensado e reaprender a aprender. Mas isso não o impede de colocar na ordem do dia o desafio para um novo modo de pensar, o qual tem um significado diametralmente ligado com a missão das luzes que foram enunciadas no século XVIII e que, de certa forma, impulsionaram os regimes democráticos e republicanos, ou mesmo as práticas de contestação e crítica às sociedades capitalistas e à racionalidade instrumental que lhes é constitutiva. A questão da (in)justiça social emerge de modo muito interligado com estes dois movimentos do mundo moderno: a busca pela liberdade, pela solidariedade e pela igualdade, de um lado, e a busca pela ampliação irrestrita e total do capital, da produtividade, da exploração, da dominação e do consumo, por outro. Esses dois grandes imaginários, como enunciou Cornelius Castoriadis (1992), constituem, de modo ambivalente e contraditório, a herança simbólica que sustenta o tecido social do mundo ocidental a partir da herança moderna.

No fundo, somos modernos porque reconhecemos, a partir de Rousseau (1978), Kant (1980), Hegel (1980) e Marx (2011), que nosso mundo é uma criação feita pelo próprio homem. Nossas instituições, em sentido semelhante, não derivam suas forças de fundamentação de um plano transcendente, estando sempre ancoradas em pressupostos discutíveis e susceptíveis de mudança e contestação. Nossa consciência acerca dos limites da modernidade e de suas contradições talvez nos coloque em uma nova condição, a qual não sabemos precisar. Para alguns, estaríamos vivendo 
um novo momento filosófico, denominado de pós-moderno (LYOTARD, 2002) ou, mesmo, uma nova condição social, pós-moderna (HARVEY, 2006). Para outros ainda estaríamos na modernidade, mas em sua fase líquida, seríamos ainda modernos, mas não teríamos as mesmas ilusões dos primeiros modernos (BAUMAN, 2001). Esta ideia da criação social e histórica, mais do que de uma definição última acerca do que melhor marca o espírito desta época, ajuda a pensar um sentido complexo para o universo da justiça social e de seu vínculo com o capitalismo, a educação e a docência. O projeto da autonomia e da emancipação proclamado pela modernidade, associado à ação da educação e dos educadores, por certo, não está acabado, mas a forma como a modernidade encarnou o imaginário social capitalista limitou e muito as ambições e conquistas emancipatórias.

Na medida em que encarnou a significação imaginária capitalista do (pseudo)domínio (pseudo)racional, a modernidade está mais viva do que nunca, engajada numa corrida frenética, a qual leva a humanidade para os mais extremos perigos [...]. O próprio projeto de autonomia, por certo, não está encerrado, nem terminado. Mas sua trajetória durante os dois últimos séculos provou a inadequação radical (para falar comedidamente) dos programas onde o capitalismo se encarnara - quer seja a república liberal, quer seja o socialismo marxista-leninista (CASTORIADIS, 1992, p. 26).

Com isso, entende-se, junto com Castoriadis, que a ideia de justiça social, assim como a de democracia, de autonomia e de direitos humanos, é uma criação social e histórica e que elas não apenas ajudam a fazer o mundo humano funcionar de certa maneira, como também ajudam a estranhar o mundo, tal como ele se apresenta, tendo em vista as possibilidades de sua mudança social. "Para o ressurgimento do projeto de autonomia", explica Castoriadis (1992, p. 26), "novas atitudes humanas e novos objetivos políticos são exigidos, cujos sinais por enquanto são raros". Nesse sentido, Bauman, na obra Vida líquida (2009), também ponderou sobre os conceitos de democracia e de finalidade da educação. Segundo ele, em uma clara menção a Castoriadis, uma sociedade democrática está invariavelmente ligada à educação e à autoeducação. Pode-se acrescentar que uma sociedade que aspira a outros níveis de justiça social também depende da educação ou, mesmo, de um grau de autocrítica gerada por ela e pelos educadores; tarefa que parece exigir uma pedagogia crítica, adverte Bauman, amparado em Giroux, a qual possibilite à sociedade "se sentir culpada" ou, mesmo, se sentir insatisfeita com as conquistas já realizadas. Nas palavras de Bauman: 
Os destinos da liberdade, da democracia que a torna possível - ao mesmo tempo que é possibilitada por ela - e da educação que produz a insatisfação com o nível de liberdade e democracia até aqui atingido são inextricavelmente ligados e não podem ser separados um do outro. Pode-se ver essa conexão íntima como outra espécie de círculo vicioso - mas é nesse círculo, e só nele, que as esperanças humanas e as chances da humanidade se inserem (2009, p. 23).

Sobre esse panorama, uma luta de fundo anima nosso esforço para pensar a justiça social em tempos de modernidade líquida/flexível e ela tem um caráter eminentemente prático, assim como eminentemente teórico. Trata-se, ao mesmo tempo, de a tornarmos efetiva, no sentido que permita conquistas e alargamentos das liberdades, combatendo desigualdades, discriminações e formas de opressão, dentro de um mundo que está em curso, como também de repensarmos, do ponto de vista teórico, o próprio significado do termo e sua relação potente com os desafios do presente. Este parece um movimento contemporâneo que tem atravessado o debate nas ciências humanas e na filosofia, ganhando destaque nos escritos de Fraser, Sen, Rawls, Dubet, entre muitos outros (ESTEVÃO, 2015).

Um sentido para a ideia de justiça social, associada ao combate das desigualdades, está bem configurada nos escritos de Dubet (2003) e de outros pensadores. Numa clara alusão a Tocqueville e a seu senso de igualdade, Dubet evidencia como este marco significativo pode servir de referência para pensar nas democracias modernas, bem como nos direitos humanos. Dubet, assim como Castoriadis (1992), distingue os dois sentidos fortes e paradoxais da modernidade, explicitando como ela comporta, de um lado, um projeto de exploração, movido pelas forças do capital, e, de outro, um projeto de autonomia, de igualdade e de emancipação, marcado pela ideia de democracia.

Um relato otimista sobre a modernidade poderia mostrar sem dificuldade que as sociedades democráticas, no sentido definido por Tocqueville, fizeram recuar pouco a pouco as desigualdades de castas e de ordens, a escravatura, a ausência de direitos políticos, a marginalização das mulheres, as aristocracias de nascimento [...]. A segunda face da modernidade é encarnada por Marx, para o qual as desigualdades de classes não constituem uma herança do passado, mas um elemento fundamental, estrutural, das sociedades modernas, isto é das sociedades capitalistas. Na medida em que o capitalismo se baseia num mecanismo de extração permanente da mais-valia a partir do trabalho, especialmente exigindo o investimento de uma parte crescente das riquezas produzidas, a oposição dos trabalhadores e dos donos dos investimentos, do trabalho e do capital, torna as desigualdades sociais um elemento funcional do sistema das sociedades modernas (DUBET, 2003, p. 25-26).

O destaque conferido por Dubet (2003) a duas tradições antagônicas para a leitura da modernidade ajuda a explicitar a natureza da análise que estamos conduzindo para pensar um outro sentido para a ideia de justiça social entre o 
referencial moderno e o pós-moderno. $\mathrm{O}$ autor, ao buscar pensar as desigualdades e seu sentido em um projeto de justiça social, marca fortemente o argumento que destaca o reconhecimento positivo das viradas para o mundo moderno. Dubet está denotando, no fundo, que a modernidade não é apenas um projeto social de cunho exploratório, mas também um ideal de igualdade e, mesmo, de liberdade, centradas em pressupostos contratuais e liberais. A expansão dos sistemas de ensino bem como a democratização dos serviços da educação, em um sentido positivo, estariam na base no enfrentamento das desigualdades e injustiças, por intermédio das igualdades de oportunidades.

O imaginário moderno, obviamente, carrega não somente sementes de liberdade e de justiça social, como também novas sementes de controle, exploração, silenciamento e regulação. Sob o ponto de vista positivo (emancipatório), o imaginário moderno é produzido por uma sociedade que busca outras formas de liberdade e igualdade e que, para tanto, cria sobre si uma autocrítica capaz de dissolver os "magmas de significados" (CASTORIADIS, 1987) que conferiam solidez ao poder instituído. Condição que permite irromper, no seio da velha Europa, uma nova forma de poder, em que o Rei, nas proximidades da Revolução Francesa (1789), "está morto", e o Clero perdeu seu lugar central na produção da hegemonia e da legitimação. "A legitimidade do rei não decorre mais de Deus, nem está fundada no próprio rei: seu poder só pode ser considerado legítimo se ele agir dentro dos limites que lhe impõe o direito baseado na moral" (KOSELLECK, 1999, p. 127). Importa destacar, como faz Bignotto (2017, p. 182), que um dos aspectos decorrentes da Revolução Francesa se refere ao constitucionalismo, juntamente com "o elogio do sufrágio universal e a afirmação dos princípios de igualdade política entre todos os cidadãos". Está-se diante do nascimento das repúblicas e das democracias modernas, sob os zelos do Estado-Nação. Ou seja, está-se diante do novo sujeito instituído pelo mundo moderno, o qual passa a figurar como principal agente de regulação das ordens política, social e educacional, o Estado-Nação.

Na interpretação de Honneth, no texto Educação e esfera pública democrática (2013), a educação deveria ser vista, por parte da filosofia política, como uma dimensão importante para a democracia e para o Estado-Nação. O autor está ciente de que a instituição dos marcos dos pensamentos político e filosófico modernos considera a questão educacional/escolar central para a funcionalidade das esferas públicas e democráticas. Na leitura de Honneth (2013, p. 545), "para Kant, o paralelo entre a arte do governo e a arte da educação resultava da consideração de que ambas são instituições criadas pela sociedade". Segundo ele, ambas "têm 
de cumprir a mesma tarefa nas dimensões diferentes da história da espécie e do indivíduo, na filogênese e na ontogênese" (HONNETH, 2013, p. 545). Esta leitura corrobora o sentido que se atribuiu ao valor da educação no âmbito do pensamento moderno e seu vínculo com a liberdade e a maioridade. Kant, depois de Rousseau, tem plena consciência de que os homens não nascem humanos, mas tornam-se humanos. Isso significa assumir que o humano, assim como o mundo humano, é uma criação; mas significa também que a ordem estatal republicana depende da educação (HONNETH, 2013, p. 546).

Para compreender as sementes de legislação, controle e regulação produzidas pela modernidade, Zygmunt Bauman, na obra Legisladores e intérpretes: sobre modernidade, pós-modernidade e intelectuais (2010), mostra a outra face ou polo do projeto social moderno. Bauman, em sua rica abordagem, evidencia como a questão da ordem tornou-se central para os construtores do mundo moderno. À escola coube a tarefa de produzir a educação necessária para construir o Estado-Nação. A crença de que era possível criar um mundo ordenado, conforme os ditames da razão, produziu, segundo Bauman, uma forma excludente e regulatória, a qual tratou de ajustar todos de acordo com os ditames do novo poder. Para Bauman, a face emancipatória da modernidade, da educação moderna, ficou subordinada à face disciplinadora e punitiva. O fundo em que Bauman (2010) se movimenta para produzir tal diagnóstico e estranhamento da modernidade é diferente do de Honneth (2013), estando muito mais próximo do de Foucault (2005) ou, mesmo, da atitude pós-moderna em geral. A questão de Bauman (2010) não é tanto o problema da igualdade, como aponta Dubet (2003), em sua leitura da política e do mundo do trabalho, tampouco o da liberdade política, como aponta Honneth (2013), mas substancialmente o problema da diferença e do poder. Com isso, Bauman coloca, na ordem do dia, uma discussão relacionada à emancipação e à justiça social, que precisa considerar: a liberdade e a diferença na interface das relações de poder. $\mathrm{O}$ pano de fundo de Bauman é, no contexto desta obra, profundamente pós-moderno e instiga a pensar a educação e a modernidade em geral por outra ótica. "A ideia de educação", conforme Bauman (2010, p. 102), "significava o direito e o dever do Estado de formar (mais bem expresso no conceito alemão de Bildung) seus cidadãos e guiar sua conduta”. Aspecto que significava, esclarece Bauman (2010, p. 102), “o conceito e a prática de uma sociedade administrada”. O propósito da educação, diferentemente do proclamado, era o de obedecer, não o de disseminar conhecimento.

Em suma, em Dubet (2003) e Castoriadis (1992), há uma análise ambivalente e contraditória da modernidade e, com ela, uma aposta radical nas vias da demo- 
cracia, tendo em vista o problema das (des)igualdades material e normativa, da autonomia e da liberdade política. Em Honneth (2013), o valor da educação é visto como forma de construir a maioridade dos sujeitos que irão governar e atuar na esfera pública, ou seja, o problema da justiça social é tratado como um problema que envolve a participação política. Honneth (2013) exacerba o polo positivo do poder do Estado, da esfera pública, e o lugar da escola e dos educadores como aqueles que propiciam esta consciência pública. Em Bauman (2010), o sentido da educação emerge como forma de criação e autocriação do mundo social moderno, tendo servido a educação muito mais como forma disciplinadora e excludente dos corpos do que forma emancipatória a serviço da liberdade e da justiça. Uma leitura muito mais negativa da modernidade emerge em Bauman, tendo em vista as ilusões do projeto social moderno e seu caráter regulatório, ordeiro e homogeneizante.

No fundo, Bauman (2010) está mostrando que há uma lacuna, ou mesmo uma cegueira, no projeto social moderno, e que esta ficou evidenciada com o alvorecer do totalitarismo no século XX e das diferentes formas de exclusão e silenciamento de culturas, etnias e povos. Trata-se, sobretudo, de uma crítica ao eurocentrismo embutido nos ideais democráticos e emancipatórios da modernidade, bem como nos modos de pensamento que produzem os imaginários sociais hegemônicos, o que acaba por subverter a forma tradicional da crítica. Mas como esta crise dos referenciais modernos, do universalismo moderno acaba por se manifestar na educação? Ela é apenas decorrente das aspirações e projetos não realizados pela modernidade ou uma consequência dos limites e entornos das próprias configurações e relações sociais e culturais implicadas com a mudança do capitalismo de uma fase nacional para uma fase transnacional? Três conjuntos de temas parecem estar envolvidos nessas questões: a) os limites ou insuficiências das configurações modernistas (eurocêntricas) em torno das ideias de democracia, liberdade, política e justiça social, as quais não configuram de forma suficiente a questão da diferença; b) a reconfiguração das formas do pensamento filosófico e científico em torno das categorias linguagem, cultura e poder; e c) a mudança social e a nova base legitimatória do capitalismo em sua fase móvel, fluída e flexível, com seu desdobramento no mundo do trabalho. Movimento que desafia a pensar outras formas de racionalidade e de sensibilidade no trato com a questão educacional na contemporaneidade. 


\section{Docência, justiça social e educação: em busca de uma nova racionalidade/ sensibilidade complexa}

A nova condição social vivida contemporaneamente tem desafiado a repensar a docência. Inúmeros teóricos estão evidenciando a necessidade de ruptura com os pressupostos tácitos que animaram a educação durante a era moderna. Como argumentou-se anteriormente, não há consenso sobre o que configura propriamente a via possível para continuar investindo na ideia de educação: se ela segue a lógica do projeto social moderno, do esclarecimento, da autonomia e da racionalidade; ou se investe nos pressupostos sugeridos pelo projeto social pós-moderno da desconstrução. O que se torna comum, neste modo de exposição, é que a ideia de justiça social tem mobilizado pensadores liberais e teóricos críticos que buscam rearticular, desde a filosofia moderna, sentidos políticos fortes, para pensar o valor da democracia, da justiça social e dos direitos humanos, tais como Dubet (2003) e Honneth (2013), bem como pensadores pós-críticos, que têm buscado argumentar a necessidade de buscar novos pressupostos para pensar a continuidade da vida democrática, tal como a proposta de Bauman (2010).

Os primeiros têm levantado as pautas da liberdade e da igualdade (DUBET, 2003) como fundamentos centrais para pensar as ideias de justiça social e democracia. Os segundos têm destacado as pautas da liberdade e da diferença (PETERS, 2000; BAUMAN, 2010) como dimensões fundamentais para enfrentar os novos tempos. O discurso educacional contemporâneo bem como o discurso filosófico em geral parecem marcados por esses posicionamentos díspares e contraditórios. Uma via possível, para interpretar os desdobramentos deste debate no âmbito da docência, é a de que, conforme se definem os papéis e fins sociais e políticos do processo de escolarização, se constituem marcas identitárias e epistêmicas para a atividade docente. Tornou-se impossível não considerar os novos temas envoltos nas problemáticas sugeridas pelas novas agendas pós-modernas, mas, da mesma forma, cumpre não abandonar por completo alguns sentidos fortes e importantes, que foram e se tornaram conquistas da própria modernidade. O próprio Bauman, na obra O mal-estar da pós-modernidade (1998), parece estar consciente que somente a defesa da diferença, separada da busca da igualdade social, tal como a pós-modernidade postula, pode resultar em mais opressão e dominação. Em suas palavras: 
A política pós-moderna, voltada para a criação de uma comunidade política viável, precisa ser guiada pelo tríplice princípio de Liberdade, Diferença e Solidariedade, sendo a solidariedade a condição necessária e a contribuição coletiva essencial para o bem-estar da liberdade e da diferença. No mundo pós-moderno, os primeiros dois elementos da fórmula tríplice têm muitos aliados abertos ou encobertos, quando nada nas pressões de "desregulamentação" e "privatização" dos crescentes mercados globalizados. Uma coisa é improvável a condição pós-moderna produzir sob sua responsabilidade - isto é, não sem uma intervenção política - é a solidariedade. Mas, sem a solidariedade [...] nenhuma liberdade é segura, enquanto as diferenças, e o tipo de "política de identidade" que elas tendem a estimular, como David Harvey ressaltou, de um modo geral terminam na internacionalização da opressão (BAUMAN, 1998, p. 256).

Safatle, na obra A esquerda que não teme dizer seu nome (2016), advoga que o direito à diferença só pode ser estabelecido a partir da defesa da igualdade e da própria agenda da modernidade. Todo o esforço do autor se localiza no sentido de pensar um conceito forte para a questão da democracia e mesmo da modernidade, a partir da defesa da igualdade. Mas ele também não deixa de reconhecer que pensar a democracia, nos novos tempos, só é possível a partir do reconhecimento da diferença. Em sentido semelhante, marcando posição de crítica radical à filosofia da diferença, Fredric Jameson (2013) argumenta que se pode pensar pela ótica da diferença, mas também é preciso pensar pela ótica da identidade. Tanto a posição de Safatle quanto a de Jameson guardam relações com a filosofia hegeliana: é preciso pensar a diferença na identidade e a identidade na diferença. Tratando da crítica pós-moderna à ilustração, Jameson (2013, p. 68) assim pondera: “[...] desde uma perspectiva dialética as duas narrativas são corretas e ambas estão igualmente equivocadas"; segundo ele, "é esta visão dupla a que se exercita a partir do pensamento negativo de Adorno [...]”. Mas, em que sentido esses debates movimentam para pensar a educação e o agir docente nos novos tempos?

As críticas desses autores emergem, em linhas gerais, como formas de uma nova via para pensar nos limites de uma ação educativa que se movia apenas pelo vértice igualitarista ou, mesmo, homogeneizante. Também têm permitido pensar que o vértice diferencialista ou de reconhecimento da heterogeneidade, não necessária ou automaticamente, é produtor de justiça social. Dubet (2008) tem argumentado em suas obras que se torna importante pensar como a escola moderna distribui o bem comum e como trata os desiguais em função dos contextos sociais e culturais. Este tipo de postura assume um cunho universalista, não somente liberal, também no que tange à crítica social. A crítica ao elitismo republicano e à defesa de uma igualdade de oportunidades para todos emerge na escritura de Dubet (2008) como uma forma de pensar sobre o que seria uma escola justa no pro- 
jeto da modernidade, tendo em vista suas contradições. Ao recuperar o processo de constituição da escola republicana na França pós-revolução francesa, Dubet (2008) evidencia como as desigualdades econômicas, no contexto da Revolução Industrial, precisam ser consideradas para poder levar a termo os ideais de busca de igualdade por meio da escolarização.

Considera-se que a criação da escola obrigatória e gratuita (1881) é uma etapa decisiva no acesso de todos os alunos à educação, mas durante um longo período nem todas as crianças tiveram acesso à mesma escola e, portanto, à mesma competição. A igualdade das oportunidades não era formalmente realizada, nem mesmo afirmada como um princípio pelos fundadores da escola republicana, porque todos os alunos não entravam na mesma arena e, portanto, não podiam vislumbrar os mesmos percursos. Com a abolição do exame de entrada na sexta série após a criação do colégio único em 1975, pode-se considerar que as condições estruturais da igualdade das oportunidades foram progressivamente realizadas [...]. Â questão das desigualdades de acesso se substitui a das desigualdades de sucesso (DUBET, 2008, p. 21).

O novo panorama contemporâneo, implicado no âmbito da escolarização, evidencia que não basta a garantia do acesso à escola como forma de assegurar o sucesso ou a igualdade social. Mesmo que esse acesso seja condição para permitir um maior nível de igualdade, ele está longe de atenuar as desigualdades sociais. Pode-se dizer simplesmente, argumenta Dubet (2008, p. 28), “que tanto na França quanto em outros lugares, a escola não conseguiu neutralizar os efeitos das desigualdades culturais e sociais sobre as desigualdades escolares". O ideário da igualdade social, por meio da escola, não é plenamente realizável em uma sociedade desigual e classista. Pensar a questão da igualdade, na interface das condições sociais e culturais deste tempo, como desafiou Adorno (1999), parece ter sido a postura teórica de Dubet (2008), para pensar no alcance do conceito de igualdade. Uma educação igual para todos, no sentido de não considerar o caráter heterogêneo dos estudantes e seu lugar social e cultural, em função da classe social e do gênero a que pertence, mostrou-se importante sob certo ponto de vista, mas uma análise complexa e profunda revela que ela manteve desigualdades. Mesmo meninas que manifestaram melhor desempenho escolar que meninos acabam se saindo pior na vida social, em função das desigualdades sociais entre os sexos. Simplesmente, adverte Dubet (2008, p. 29), "a escola não consegue escapar à pressão das desigualdades sociais".

Em sentido semelhante ao de Dubet (2008), Mariano Enguita (2004) procura compreender como a desigualdade social e as políticas igualitárias estão relacionadas com a injustiça no contexto da escolarização. No projeto da modernidade, 
Enguita critica tanto Voltaire quanto Rousseau, manifestando que o primeiro foi um crítico da educação para os pobres, e o segundo não levou sua preocupação com a educação além dos limites da nobreza. Na base da crítica de Enguita (2004), há o entendimento de que a expansão da escola veio acompanhada da ideia de que diferentes grupos sociais deveriam receber educação diferente. Os povos colonizados, as mulheres, os pobres, não estavam contemplados no início do processo de escolarização. Para as classes populares, coube um tipo de educação, as escolas elementares; paras as classes favorecidas, outro, os institutos, os liceus. Para as primeiras, surgiram as escolas técnicas; para as segundas, os bacharelados. Uma divisão social se produziu no interior do sistema educacional (ENGUITA, 2004, p. 76). Essa leitura de Enguita procura mostrar como a escola precisa ser interpretada não somente no que tange ao seu papel de reprodução social, como também no seu poder de transformação social. Nesse sentido, Enguita evidencia como a questão da justiça social parece requerer, além da igualdade (como forma homogeneizante), a questão da liberdade, da diversidade e da responsabilidade. Em sua retomada histórica sobre o problema da justiça social e das políticas igualitárias, ele mostra como a centralidade do debate até as décadas de 1970 e 1980, na Espanha, estava relacionada com as desigualdades de classe. Pouco a pouco, abriu-se o caminho para outro tipo de desigualdades, "especificamente as de gênero, primeiro e as étnicas, depois" (ENGUITA, 2004, p. 79). O autor acrescenta que este movimento em torno da igualdade escolar alcançado pelas mulheres, embora importante para suas demandas nos âmbitos políticos, sociais e econômicos, permitindo combater argumentos patriarcais, ainda merece ser problematizado.

Mas esse tipo de igualdade é, por assim dizer, fácil; consiste essencialmente em não fazer nenhuma distinção, em tratar todos de forma burocraticamente igual. Como em geral, consistiu apenas em escolarizar mais gente, por mais tempo e com mais meios, encontrou apoio inequívoco em alguns professores - e em alguns aspirantes a professores - para os quais era sinônimo de melhorias trabalhistas e maiores oportunidades profissionais. $\mathrm{O}$ problema ocorre quando, por um lado, é preciso compatibilizar a igualdade com a liberdade e a responsabilidade; por outro, quando, ao passar das palavras aos fatos, esbarra-se, dentro e fora da instituição, com a diversidade do público potencial e real (ENGUITA, 2004, p. 83).

Curieses, no texto Por una escuela inclusiva (2017), projeta um significado amplo para a ideia de educação inclusiva, demarcando com mais força que Enguita (2004) a questão da diversidade a partir da crítica que o feminismo pós-moderno endereça à educação. Segundo ela, "si bien es reconocido el derecho a la educación de todas las personas, siguen siendo numerosas las voces que reclaman la necesidad de pensar, estudiar, proponer y comprometerse con nuevas formas de entender 
y enfocar la educación de la diversidad del alumnado. Así, surge la idea de una escuela inclusiva" (CURIESES, 2017, p. 2). Se Enguita mostrava como a questão de classe perdia força a partir da década de 1970, Curieses mostra como a questão de gênero emerge a partir dos anos 1960. Importa, para este estudo, marcar como o cenário educacional é modificado a partir desta discussão, e como os professores são provocados para pensar questões novas em torno das políticas de identidade. Segundo Curieses (2017, p. 5): "Las diferencias habituales entre los seres humanos componen una sociedad de diferentes que obliga a aprender a vivir en el respeto a esas diferencias, buscando en ellas motivos y causas de enriquecimiento para todos".

Importante notar que, se o deslocamento interpretativo feito por Dubet (2003) e Enguita (2004) leva a problematizar questões de classe, ou mesmo econômicas, como fundantes dos problemas das desigualdades, inclusive as de gênero e étnicas, o debate feito por Curieses coloca o problema da linguagem, da diferença e da representação na anterioridade do problema envolvido na mudança social. A referência para o debate remete ao enfoque pós-moderno, tornando-se as questões do corpo, da sexualidade e do poder centrais para pensar o sentido que o termo diferença representa. Michel Foucault e Judit Butler tornam-se os protagonistas desta virada na teorização contemporânea.

Foucault presentó una manera diferente de concebir y percibir las teorías acerca del yo y de la sociedad, conjugándolo con un nuevo método de evaluación. Pero su método conduce a una práctica de autorrechazo: a pensar contra nuestra propia identidad, sospechosa de estar al servicio del poder en tanto que participa del mismo, al servicio de intereses patriarcales y de ser, por extensión, opresora. La identidad y el género aparecen como algo sumamente complejo, estando en juego con el poder, lo que supone una dificultad para pensar en la resistencia al mismo. Pero, si bien el poder produce y somete, la producción que lleva a cabo el poder de los sujetos no siempre tiene el resultado esperado. Y esto es lo que va a interesar a Butler: precisamente el fracaso de los propósitos del poder. Judit Butler ofrece un punto de vista desde el que es posible desarticular el determinismo social que niega la posibilidad de que el agente actúe y cambie (CURIESES, 2017, p. 6.)

A reconfiguração do campo educacional, sob a ótica pós-moderna, não somente amplia a agenda, como também reconfigura o que está em questão na prática educativa dos educadores, quando se fala de democracia e justiça social. Como argumentado, se alguns autores permitem pensar sobre o desafio de conceber a busca da igualdade e da liberdade a partir dos marcos da modernidade, ou mesmo do pensamento crítico sobre ela, outros buscam pensar e projetar para além dos modos críticos tradicionais, incorporando a questão da liberdade e da diferença. Torna-se bastante presente nas novas configurações teóricas uma capacidade do- 
cente para pensar como se dão os processos de exclusão não somente em termos das desigualdades sociais, ou mesmo como elas são produzidas nas malhas da economia política, como também no âmbito das produções discursivas e culturais que instituem e produzem identidades. Uma capacidade pós-crítica para perceber que não há nem deve haver referentes fixos ou padronizados na linguagem (DERRIDA, 2016) para a produção das vidas social e individual torna-se o desafio para pensar as "práticas inclusivas na escola” (CURIESES, 2017, p. 7).

A problemática da dominação colonial ganha destaque na nova agenda. As questões ligadas ao corpo, ao gênero, à etnia, à sexualidade e ao poder entram na agenda do dia. $\mathrm{O}$ marco da problemática educacional é praticamente reconfigurado. Não é mais possível compreender as questões ligadas à justiça social pensando apenas em problemas de classe social, trabalho e ideologia. A nova teorização, envolta no âmbito dos estudos culturais, coloca o tema dos diferentes e das minorias excluídas no interior da agenda e do debate sobre o decurso civilizatório. Está-se diante e desafiado a pensar a educação do corpo ou, mesmo, as práticas discursivas que constituem e fundamentam as tecnologias produtoras do eu (SILVA, 1995). Todo o alicerce filosófico que sustentou o discurso pedagógico moderno é desnaturalizado. Com uma percepção muito aguda para as questões do universo contingente, as novas fundamentações filosóficas abrem temas pouco considerados pela agenda emancipatória moderna. No sentido revolucionário do termo, Kincheloe (1997, p. 15) procura entender que:

O pensamento pós-moderno submete a análise das formas sociais e educação ao ethos modernista pré-existente. Admite que a conversação cultural previamente proibida se evidencia a partir de novas questões feitas por vozes antes excluídas. Os pensadores pós-modernos desafiam a estrutura hierárquica do conhecimento e do poder, a qual promovem os especialistas sobre massas procurando novos caminhos para conhecer que transcendam os fatos empiricamente verificados e "razoáveis", argumentos lineares colocados na busca pela certeza. Quando o pós-modernismo está baseado num sistema crítico de sentido que está preocupado com um conhecimento questionador que procura entender criticamente a si mesmo e a sua relação com a sociedade ele torna-se uma ferramenta poderosa para uma mudança social progressista. Ao fazer isso ele muda as situações sociais que impedem o desenvolvimento de comunidades igualitárias e democráticas marcadas com a justiça econômica e social.

Embora se possa dizer que os problemas filosóficos se colocam, em um plano, como distintos, para não dizer totalmente incompatíveis, em outro plano, eles tornam-se desafios para os sujeitos que lidam com eles em suas práticas educativas, a partir dos marcos das políticas educacionais e dos movimentos do mundo social e histórico. Ou seja, se, por um lado, é possível compreender que o enfoque 
pós-moderno colocou em questão toda a agenda moderna em torno da noção de sujeito, de verdade e de razão, de outro é possível compreender que ele não deixou de sugerir novos temas para a questão democrática a partir das ideias de identidades, diferenças e alteridades. Guinada que obviamente coloca em crise o estatuto e o formato das teorias e ambições modernistas. A ideia de justiça social parece desafiar a não somente incorporar uma nova agenda para pensar e intervir nos problemas educacionais, como também exigir reconstruir as tradicionais temáticas da modernidade no que tange à busca da igualdade, da liberdade e da fraternidade. Na seguinte passagem, Santamaría-Goicuria e Stuardo-Concha (2018, p. 3), autores que discutem a ideia de justiça social tal como as projetadas pelas políticas de reconhecimento de Fraser e Honneth, desdobram desafios contemporâneos para a educação que já incorporam os problemas da busca da igualdade e de reconhecimento da diferença no âmbito do agir docente:

Las propuestas teóricas de Justicia Social como un asunto de redistribución se focalizan en las acciones para repartir. Su punto de interés está en desarrollar principios de justicia que permitan corregir la privación de recursos y que estos sean mejor distribuidos en función de los distintos intereses [...]. Las propuestas de Justicia Social que enfatizan el reconocimiento se focalizan en cuestiones vinculadas a la aceptación y al respeto de las diferencias, ya sean de tipo identitarias, culturales o de otra índole. Tienen como objetivo lograr la ausencia de dominación cultural, combatir el no reconocimiento de derechos y promover la valoración y respeto de aquello que es diferente [...]. Desde esta visión se plantean principios de justicia que permitan considerar las relaciones sociales que se establecen entre los seres humanos. El énfasis está en resolver demandas de tipo simbólico-culturales, muy vinculadas a procesos de representación, interpretación y comunicación. La mirada desde el reconocimiento analiza los problemas considerando la existencia de grupos sociales diferentes entre sí en función de sus rasgos identitarios y culturales compartidos como género, sexualidad, etnia, raza, clase social, entre otros, aunque también se advierte sobre la posibilidad de caer en la simplificación de las identidades, proceso denominado reificación [...].

Essa posição, cumpre destacar, é um pouco diferente da de Curieses (2017), assinalando posturas que articulam políticas de redistribuição (igualdade) junto com políticas de reconhecimento da diferença. Para dar continuidade à reflexão acerca das heranças modernistas, cumpre lembrar que a ação docente na modernidade sólida (BAUMAN, 2001), embora embalada e sustentada, no fundo, por princípios ligados à liberdade do indivíduo e à busca de sua igualdade, a partir da ideia de Direito, esteve bastante tutelada pela ideia do Estado-Nação. Muito do que se entendeu por educação e sentido de formação não ultrapassou a esfera das formações científica e disciplinar dos educadores. Os conteúdos éticos e políticos implicados na esfera do conhecimento e da formação não foram a tônica da modernidade em geral. Uma perspectiva bastante formalista e, possivelmente, reificante se fez em torno da 
docência, a qual manteve ausente a reflexão sobre o mundo social e histórico, bem como o mundo do trabalho e os sentidos filosófico, político, moral e histórico-cultural da educação. A retomada dos estudos sobre justiça social recoloca as questões em torno de conhecimentos importantes para pensar a formação de professores.

Sublinha-se também que, embora se possa dizer que o movimento da educação escolar tornou-se constitutivo tanto de formas de inclusão e mobilidade social quanto de reprodução e de dominação social e cultural, no âmbito do projeto social sólido-moderno, principalmente no que tange ao momento de Estado de Bem-Estar Social (século XX), ele passa por uma crise no contexto das sociedades líquido-modernas (final do século XX e início do XXI). A crise do projeto social moderno, com o advento do neoliberalismo e das sociedades globalizadas, modificou e muito as promessas de universalização e garantia de direitos dos indivíduos. A nova linguagem parece prescindir da educação escolar como direito público fundamental e, sobretudo, parece colocar a educação sob os critérios das economias de mercado. Se a mercantilização da educação corrói o último elemento marcante ainda remanescente do projeto social sólido-moderno, cumpre pensar o destino que incumbe aos sujeitos e ao mundo no avançar das sociedades ligadas ao espírito (ir)racional do capitalismo contemporâneo. Sob este aspecto, Santamaría-Goicuria e Stuardo-Concha (2018, p. 5) compreendem o significado do processo de escolarização e da ação docente.

Visto esto, y en el marco de una sociedad líquida y una educación influida por principios neoliberales de competitividad e individualismo, observamos que vivimos en una sociedad que no contempla el término justicia social, en algunos casos, o lo contempla de manera limitada a asuntos de distribución de recursos y oportunidades en otros. Este contexto nos ha hecho replantearnos la responsabilidad que la escuela en general y sus docentes en particular tenemos en el proceso de recuperación social. Junto con Freire (1978, p. 3) tenemos esperanza en una educación como praxis, reflexión y acción del hombre sobre el mundo para transformarlo. Si bien la educación por sí misma no puede lograr la transformación social, sin ella tampoco se daría [...].

Os novos movimentos do capital em escala global têm permeado todas as dinâmicas das vidas social e cultural, mercantilizando e unificando formas de vida que passam a operar conforme as lógicas dominantes. Um dos grandes impactos das novas formas de vida social tem sido percebido em torno das vidas política e moral das sociedades. $\mathrm{O}$ destino do mundo tem sido cada vez mais conduzido por forças externas e estranhas às lógicas das comunidades, dos povos, das culturas e das nações. O poder tem se tornado extraterritorial e cada vez mais está afastado da esfera pública (BAUMAN, 2001). Um sentido possível e valioso em torno da vida pública e das liberdades políticas tem se perdido em meio ao crescimento voraz 
das culturas de consumo. Os intelectuais críticos que advogam em torno do valor da liberdade, da diferença, da solidariedade, da igualdade e da sustentabilidade como metas fundamentais da educação, reconceitualizando os ideais modernos (sem abandoná-los por completo) a partir dos novos pensamentos pós-modernos, percebem a atualidade e a necessidade de constituir educadores com perfis ligados à ideia de justiça social. Zeichner (2008) é um desses educadores que tem se ocupado com uma agenda de investigação/formação de educadores relacionados com a justiça social. Acrescenta-se a esta agenda a necessidade de educadores que saibam traduzir e interpretar diferentes tradições que disputam os cenários filosófico e educacional, a fim de construir discursos e práticas menos reducionistas, ou seja: para que a luta pela igualdade não seja em detrimento da diferença, e a luta pelo reconhecimento da diferença não seja em desmerecimento da igualdade; para que a luta por liberdade política não signifique o esquecimento das classes sociais e das imensas desigualdades produzidas pelo capitalismo global em sua relação com o mundo do trabalho; em suma, para que se tenha a capacidade de questionar aspectos imaginários e ideológicos do próprio discurso educacional, percebendo como evidenciam/ocultam as lutas em torno do poder e da liberdade.

\section{Considerações finais}

$\mathrm{O}$ recorte feito ao longo do texto permitiu retomar a ideia de justiça social como uma possível forma que tem sido utilizada tanto por pensadores modernos como pós-modernos para refletir a educação e o sentido da intervenção educacional. De estirpe claramente política, mas encharcado de moralidade, o debate em torno da justiça social conclama uma reflexão que está além dos códigos normativos da modernidade. Trata-se de questionar o não realizado da modernidade, de apontar a negatividade embutida nos processos da modernização conservadora, a qual, de uma parte, assegura a individualidade e o direito à liberdade para poucos, colocando as imensas maiorias à margem dos processos emancipatórios, de outra, aponta as promessas da modernidade, de sua idealidade, de sua aposta imaginária, consubstanciada em seus aparatos jurídico e constitucional.

Neste esforço interpretativo, as sociedades sólido-modernas, emergentes do século XVI, configuraram uma importância capital para o problema da educação. Ela se tornou uma forma de criação do humano e do mundo social e histórico. Dois imaginários compõem o cenário contraditório e ambivalente da vida social moderna: a emergência das democracias e a do capitalismo industrial. Em um 
aporte claramente articulado com a proposta modernista, alguns pensadores da atualidade buscam rever o projeto kantiano ou, mesmo, do idealismo alemão como uma forma de continuar pensando no valor do liberalismo, do contratualismo e do republicanismo para organizar a justiça, o direito e a política democrática. Essa retomada não ocorre sem críticas e sem outras considerações mais amplas. Tentou-se argumentar que os imperativos que demarcaram as grandes significações para o processo de escolarização em seu sentido político acabaram por influenciar os sentidos e finalidades da ação docente e dos saberes que lhe são constitutivos.

De uma parte, evidenciou-se o caráter limitado das políticas de igualdade que movimentaram a agenda de escolarização das sociedades modernas, de outra, mostrou-se como elas permitiram alguns avanços em termos de mobilidade social e liberdade democrática. Entendeu-se como o movimento pós-moderno, ou a atitude pós-moderna, possibilitou a entrada de questões novas em relação à democracia e à justiça social. Argumentou-se que a questão da diferença, ou mesmo da filosofia da diferença, se tornou um pressuposto central para continuar pensando nos limites das modernidades filosófica e educacional. Mesmo que as questões ontológicas da pós-modernidade não tenham sido assumidas em sua plenitude, a problemática sugerida por este movimento acabou por ser redimensionada no âmbito do espaço público. Uma educação voltada ao combate do preconceito e da discriminação contra gays, lésbicas e prostitutas, bem como à inclusão de mulheres, negros e índios nos espaços antes destinados apenas às elites brancas configura um pouco do desenho contemporâneo que desafia a docência. Uma nova política de reconhecimento, amparada em autores que discutem justiça social, incorpora parte da agenda modernista, valorizando a participação igualitária dos cidadãos nos espaços públicos (liberdade e política), abarcando a luta pelo combate à desigualdade na educação escolar e na vida social (liberdade e igualdade), bem como incorpora parte da agenda pós-modernista, questionando lugares e formas opressivas de poder e de saber (liberdade e diferença), que, em nome da emancipação, promovem opressão e desvalor identitário de grupos minoritários.

As sociedades líquido-modernas (BAUMAN, 2001), no século XXI, em seu sentido político, parecem ter configurado uma abertura para essas questões novas, ao mesmo tempo em que as liquefazem no âmbito de sua dinâmica econômica. Se novas pautas políticas emergem e desafiam os educadores a pensar nas identidades de corpo, gênero, etnia e classe social, estes vivem o sintoma do mal-estar docente no âmbito do seu quefazer. A desvalorização do sentido e do trabalho docente tem sido acompanhada por um sentimento de impotência em relação ao destino social 
das maiorias e minorias. Ou seja, vive-se um momento ambíguo em relação à identidade docente: em parte, ela é o núcleo de um projeto social de esperança e inclusão social, que reconfigura os imaginários modernos e pós-modernos da educação em torno de valores e princípios democráticos, tais como: liberdade, igualdade, diferença e sustentabilidade; e, em parte, ela é desregulamentada e liquefeita pelo mercado e pelo consumo de bens materiais, sendo desvalorizada e tornada parte de um núcleo funcional que a liga direta e unicamente com a economia.

Esta funcionalização da docência, no cenário de aceleração do tempo social, desafia a repensar o núcleo identitário da docência, tendo em vista uma compreensão do seu envolvimento com as questões do mundo social e histórico. Mais do que pensar a docência ou a educação escolar como um mundo à parte, ou apenas normativo, cumpre pensar em como ela se presentifica nos dramas e nas dores do presente. Isso significa, sobretudo, considerar os papéis ativo e crítico da ação docente em relação ao curso do mundo social e histórico (CASTORIADIS, 1992) e suas relações com o mundo do trabalho (SAVIANI, 2000; ENGUITA, 2004), as subjetividades (BAUMAN, 2009) e o universo das ciências (MORIN, 2001).

Parte da teorização contemporânea procura se movimentar pela defesa do direito a aprender e pela defesa da igualdade, a partir da constituição e do contrato social moderno como formas que estariam dentro da agenda moderna. E parte da teorização tem mostrado o quanto essa agenda está e esteve comprometida com os ideais da colonização e da dominação tipicamente modernos e europeus. No primeiro sentido manifesto, argumentou-se, a partir de Honneth (2013) e Dubet (2003), um sentido para pensar no valor da educação escolar como forma de autogoverno e de produção de índices maiores de autonomia e menores de desigualdade. No segundo sentido, argumentou-se, a partir de Curieses (2017), como a questão da educação inclusiva passou a indicar novos aportes para pensar a justiça social e, mesmo, a democracia, a partir da filosofia da diferença. Evidenciou-se ainda como Santamaría-Goicuria e Stuardo-Concha (2018) já articulam no interior do debate não apenas o problema do reconhecimento da diferença, como também as políticas de redistribuição (igualdade).

Essa dupla guinada tem tornado a tarefa de pensar a docência e os saberes que a constituem altamente complexa, por ter de compatibilizar diferença com igualdade e liberdade. Por um lado, ela é levada a participar dos domínios da vida social e cultural, problematizando os campos discursivos que fundam as várias políticas de dominação (GIROUX, 2003) produtoras de injustiças e negam o direito às diferenças (política cultural). Por outro, ela é levada a compartilhar um bem 
comum ou, mesmo, um conhecimento poderoso (YOUNG, 2007), que lhe permite outra forma de entrada na esfera pública (cultura política). Para compatibilizar tarefa tão contraditória entre a atitude modernista e a pós-modernista, cumpre sempre problematizar as mediações histórico-sociais que produzem desigualdades ou negam as singularidades e diferenças pela força das uniformizações do mercado, do mundo do trabalho e da economia. Essa tarefa sempre pode ser conduzida, tendo em vista os desafios implicados com uma agenda que amplie e assegure as liberdades e os direitos civis, sociais e políticos ou com uma pedagogia que escute e dê voz a grupos excluídos e subalternos (APPLE; BURAS, 2008).

Esse panorama demanda, sobretudo, no âmbito da formação de professores, uma capacidade hermenêutica, dialética e complexa, para interpretar, distinguir e religar diferentes tradições de pensamento (teorias), a fim de dialogar de modo mais profundo com a "realidade" do mundo e com os estudantes em suas formas plurais e singulares de ser. Em outras palavras, os novos tempos líquido-modernos estariam requerendo uma formação ampla e geral em torno da filosofia e das ciências humanas, bem como da pedagogia, que permita aos educadores problematizar os desafios implicados no âmbito da vida ética e política de uma sociedade/cultura (mundo social e histórico) na interface das reconfigurações do mundo do trabalho, da cultura e do universo das ciências/tecnologias.

Em suma, os sentidos implicados na ideia de justiça social desafiam os educadores a não apenas compreender o curso dos acontecimentos nas quatro esferas do mundo humano, como, fundamentalmente, reconfigurar e avaliar seus modos de intervenção crítica na realidade educacional, tendo em vista o combate das (in) justiças globais, culturais e contingentes. Isso, no entendimento de Edgar Morin (2001), exigiria dos educadores mais do que ser meramente um funcionário ou, mesmo, um especialista, para propriamente desenvolver uma missão pública, a qual parece requerer uma ideia de eros e amor à humanidade, além de uma permanente análise do conhecimento ensinado (autocrítica da razão).

\section{Referências}

ADORNO, T. Mensagens numa garrafa. In: ZIZEK, S. Um mapa da ideologia. Rio de Janeiro: Contraponto, 1999. p. 39-50.

ADORNO, T. Dialética negativa. Rio de Janeiro: Jorge Zahar, 2009.

APPLE, M. W.; BURAS, K. L. Currículo, poder e lutas educacionais. Porto Alegre: Artmed, 2008. 
BAUMAN, Z. O mal-estar da pós-modernidade. Rio de Janeiro: Jorge Zahar, 1998.

BAUMAN, Z. Modernidade líquida. Rio de Janeiro: Jorge Zahar, 2001.

BAUMAN, Z. Vida líquida. 2. ed. Rio de Janeiro: Jorge Zahar, 2009.

BAUMAN, Z. Legisladores e intérpretes: sobre modernidade, pós-modernidade e intelectuais. Rio de Janeiro: Jorge Zahar, 2010.

BIGNOTTO, N. Revolução Francesa e Constitucionalismo. In: AVRITZER, L. et al. Dimensões políticas da justiça. 2. ed. Rio de Janeiro: Civilização Brasileira, 2017. p. 177-186.

CASTORIADIS, C. As encruzilhadas do labirinto 2: os domínios do homem. Rio de Janeiro: Paz e Terra, 1987.

CASTORIADIS, C. O mundo fragmentado: as encruzilhadas do labirinto 3. Rio de Janeiro: Paz e Terra, 1992.

CURIESES, P. Por una escuela inclusiva. Las fronteras del género. Revista Internacional de Educación para la Justicia Social (RIEJS), Madrid, v. 6, n. 2, p. 63-79, 2017.

DERRIDA, J. Observações sobre desconstrução e pragmatismo. In: MOUFFE, C. Desconstrução e pragmatismo. Rio de Janeiro: Mauad X, 2016.

DUBET, F. As desigualdades multiplicadas. Ijuí: Editora Unijuí, 2003.

DUBET, F. O que é uma escola justa? A escola das oportunidades. São Paulo: Cortez, 2008.

ENGUITA, M. F. Educar em tempos incertos. Porto Alegre: Artmed, 2004.

ESTEVÃO, C. A. V. Das denúncias aos anúncios. In: ENS, R. T.; BONETI, L. W. Educação e justiça social. Ijuí: Editora Unijuí, 2015. p. 31-53.

FOUCAULT, M. Em defesa da sociedade. São Paulo: Martins Fontes, 2005.

GADAMER, H.-G. O problema da consciência histórica. Rio de Janeiro: Fundação Getúlio Vargas, 1998.

GIACÓIA JUNIOR, O. A ética na era da globalização à luz do pensamento de Adorno. In: LASTÓRIA, A. C. N.; DA COSTA, B. C. G.; PUCCI, B. (org.). Teoria Crítica, ética e educação. Piracicaba/Campinas: Unimep/Autores Associados, 2001. p. 67-84.

GIROUX, H. A. Atos impuros: a prática política dos estudos culturais. Porto Alegre: Artmed, 2003.

HARVEY, D. Condição Pós-Moderna. São Paulo: Edições Loyola, 2006.

HEGEL, G. W. F. Conceito da História da Filosofia. In: Introdução à História da Filosofia. São Paulo: Abril Cultural, 1980. p. 315-392.

HONNETH, A. Educação e esfera pública democrática. Um capítulo negligenciado da filosofia política. Revista Civitas, Porto Alegre, v. 13, n. 3, p. 544-562, set./dez. 2013.

KANT, I. Crítica da Razão Pura. São Paulo: Abril Cultural, 1980. 
KINCHELOE, J. L. A formação do professor como compromisso político: mapeando o pós-moderno. Porto Alegre: Artes Médicas, 1997.

KOSELLECK, R. Crítica e crise: uma contribuição à patogênese do mundo burguês. Rio de Janeiro: EDUERJ, Contraponto, 1999.

JAMESON, F. Valencias de la dialéctica. Buenos Aires: Eterna Cadência, 2013.

LYOTARD, J. F. A condição pós-moderna. 7. ed. Rio de Janeiro: José Olympio, 2002.

MARX, K. Crítica da filosofia do direito de Hegel. São Paulo: Boitempo Editorial, 2005.

MARX, K. O 18 Brumário de Luís Bonaparte. São Paulo: Boitempo Editorial, 2011.

MARX, K.; ENGELS, F. A ideologia alemã: crítica da mais recente filosofia alemã em seus representantes Feuerbach, B. Bauer e Stirner, e do socialismo alemão em seus diferentes profetas (1845-1846). 1ª reimpr. Tradução Rubens Enderle, Nélio Schneider, Luciano Cavini Martorano. São Paulo: Boitempo Editorial, 2009.

MORIN, E. A cabeça bem feita: repensar a reforma, reformar o pensamento. 5. ed. Rio de janeiro Bertrand Brasil, 2001.

PETERS, M. Pós-estruturalismo e filosofia da diferença. Belo Horizonte: Autêntica, 2000.

RORTY, R. Para realizar a américa: o pensamento de esquerda no século XX na América. Rio de Janeiro: DP\&A, 1999.

ROUSSEAU, J. J. Discurso sobre a origem e os fundamentos da desigualdade entre os homens. 2. ed. São Paulo: Abril Cultural, 1978.

SAFATLE, V. A esquerda que não teme dizer seu nome. São Paulo: Três Estrelas, 2016.

SANTAMARÍA-GOICURIA, I.; STUARDO-CONCHA, M. Una Mirada a Prácticas Docentes desde un Marco de Justicia Social. Revista Internacional de Educación para la Justicia Social (RIEJS), Madrid, v. 7, n. 1, p. 177-196, 2018.

SAVIANI, D. Escola e democracia: teorias da educação, curvatura da vara, onze teses sobre educação política. 33. ed. Campinas: Autores Associados, 2000.

SILVA, T. T da. O projeto educacional moderno: identidade terminal? In: VEIGA-NETO (org.). Crítica pós-estruturalista e educação. Porto Alegre: Sulina, 1995. p. 245-260.

ZEICHNER, K. M. Formação de professores para a justiça social em tempos de incerteza e desigualdades crescentes. In: DINIZ-PEREIRA, J.; ZEICHNER, K. M. Justiça social: desafio para a formação de professores. Belo Horizonte: Autêntica, 2008. p. 11-34.

YOUNG, M. Para que servem as escolas? Educação e sociedade, Campinas, v. 28, n. 101, p. 1287-1302, set./dez. 2007. Disponível em: http://www.scielo.br/scielo.php?pid=S0101$-73302007000400002 \&$ script=sci_abstract\&tlng=pt. Acesso em: 25 mar. 2019. 